\title{
New Service Development: The Supplier Capability Approach
}

\author{
Outi Nuojua ${ }^{1} \&$ Jaana Tähtinen ${ }^{1}$ \\ ${ }^{1}$ Department of Marketing, Oulu Business School, University of Oulu, Oulu, Finland \\ Correspondence: Outi Nuojua, Department of Marketing, Oulu Business School, University of Oulu, Oulu, Finland. \\ E-mail: outi.nuojua@oulu.fi
}

Received: March 7, 2013

Accepted: April 11, $2013 \quad$ Online Published: April 27, 2013

doi:10.5430/jms.v4n2p34

URL: http://dx.doi.org/10.5430/jms.v4n2p34

\begin{abstract}
The aim of this study is to identify a supplier's new service development capabilities and detail the means of capability development. Currently, most research stresses the active role of a customer in new service development. However, a service supplier needs to develop new service development capabilities to enable and enhance that active role. We use a multiple case study to detect such capabilities in a technological service setting. As a result, the study categorizes the capabilities into service-, structure- and interaction-based new service co-creation capabilities and finds interaction to be an important contributor to their development. The study provides tentative tools for managers that seek to involve their customers in the new service development process.
\end{abstract}

Keywords: new service development, supplier's capabilities, capability development

\section{Introduction}

The development of new services is intricate since both explicit and, particularly, latent customer needs can fluctuate strongly (Matthing, Sandén, \& Edvardsson, 2004). Thus, the character of the service industry has changed to be more oriented towards involving customers in new service development (NSD) in order to increase the success of the services (Carbonell, Rodriguez-Escudero, \& Pujari, 2012, 2009). The active role of a customer, in turn, requires interaction and the establishment of a close and trusting relationship (Carbonell et al., 2012; Matthing et al., 2004; Nicolajsen \& Scupola, 2011). Thus, this change requires a service supplier to develop its capabilities to enable and enhance the active role of its customers. Even though NSD with customers has attracted research attention, studies have mostly focused on customer participation and input (e.g., Alam \& Perry, 2002; Carbonell et al., 2012; Nicolajsen \& Scupola, 2011) such that the relevance of supplier capabilities and the ways they develop have not been sufficiently explored.

On the other hand, capability studies concentrate on suppliers of products (e.g., Coviello \& Joseph, 2012; Croom, 2001; Lin \& Huang, 2013) and capabilities related to NSD have been neglected even though the characters of services make their development processes distinct (Martin \& Horne, 1993). Scholars note that service providers must develop dynamic capabilities (Teece, Pisano, \& Shuen, 1997) as they are required for service innovation (den Hertog, van der Aa, \& de Jong, 2010; Kindström, Kowalkowski, \& Sandberg, 2012). Johnsen and Ford (2006) study on interaction capabilities suggests that they are best developed through interaction with other parties. Hence, the NSD capabilities of service suppliers may be best developed through cooperation with their customers. For the above reasons, this study both identifies the capabilities that support NSD with customers and details the means of developing the capabilities.

The study is structured as follows. The theoretical part connects NSD that involves customers and the capabilities that are required of service companies and their development. Thereafter, the research methodology and key findings of the study are discussed and recapitulated. Finally, the study concludes with theoretical and managerial implications, coupled with an evaluation of the study and future research avenues.

\section{Theoretical Starting Points}

Although the creation of services that satisfy the needs of customers is a basic requirement, it remains complicated to couple changing customer needs with the complex nature of services (Matthing et al., 2004). As a result, continuous collaboration and learning from and with customers (Matthing et al., 2004) is required to discover both expressed and latent customer needs (Slater \& Narver, 1998). New service development is thus a process that requires continuous adaptation to evolving customer needs (Kindström et al., 2012). 
Recent studies have elaborated on the role of customers in the service innovation process (Martin et al., 1999) and the effect (Carbonell et al., 2009), results (Matthing et al., 2004), and conditions needed for customers to be involved (Alam \& Perry, 2002; Carbonell et al., 2012; Nicolajsen \& Scupola, 2011). In addition, the capabilities that service suppliers need to enable active customer participation also merit research attention.

So far, capability studies have tended to concentrate on either products (e.g., Coviello \& Joseph, 2012; Croom, 2001; Lin \& Huang, 2013) or service innovations without consideration of how NSD, particularly with customers, is undertaken. Scholars note that NSD competence (Menor \& Roth, 2007) and the capability to sense, seize, and reconfigure are essential for service innovations (Kindström et al., 2012). In addition, supplier capabilities to identify customer needs and technological options, conceptualize, (un-)bundle services, orchestrate, scale and stretch service innovations, and learn and adapt have been proposed as means to help service providers to deliver successful services (den Hertog et al., 2010). However, the capability to collaborate with customers in NSD processes remains under-researched.

Thus, this study adopts the perspective of Matthing et al. (2004, p. 487) on customer involvement and understands NSD as "processes, deeds and interactions where a service provider collaborates with current (or potential) customers to learn about the market and alter organizational behavior." NSD thus has indirect positive effects on service outcomes by influencing operational routines (Carbonell et al., 2009) and providing valuable customer information (Matthing et al., 2004). As NSD requires significant interaction and thus the establishment of a close and trusting customer relationship, a service company needs the capability to initiate, manage, apply, and (if required) terminate customer relationships. Hence, capabilities that can support the service relationship (e.g. Croom, 2001; Jarratt, 2004; Johnsen \& Ford, 2006), and thus NSD, are required.

NSD capabilities enable a service provider to deploy resources and routines to create a desired new service (Menor \& Roth, 2007). It is important to understand the services context - a structured dyadic relationship between the service provider and the customer-when studying NSD capabilities and their development. Hence, this study integrates the dyadic capability framework of Croom (2001) for new product development into the service context. Accordingly, NSD capabilities can be categorized as service-, structure-, or interaction-based capabilities. Service-based capabilities refer to the technological dimensions of a new service; structure-based capabilities refer to the methods of structuring the interaction; and interaction-based capabilities refer to the expertise of organizations relating to interaction and communication, problem-solving methods, and relationship development.

Studies on capabilities are predominantly concerned with the contribution of capabilities to securing a sustainable competitive advantage for a company. Scholars (e.g., Johnsen \& Ford, 2006; Ritter \& Gemünden, 2003) also claim that capabilities alone may not be sufficient to secure the differentiation of a company, since a company also requires distinct skills and qualifications as well as the capability to use them efficiently. Still, the question of how capabilities are developed has not received much attention (Johnsen \& Ford, 2006). The few studies that do address these issues suggest that capabilities either evolve (Zollo \& Winter, 2002) or that distinctive capabilities are developed on various paths (Eisenhardt \& Martin, 2000; Wang \& Ahmed, 2007). The relationship and network approach (Gadde \& Håkansson, 2001, pp. 81-85) implies that capabilities developed internally and those acquired through relationships have multiple and complex interfaces. Capability development is hence seen as taking place during the interaction between the relationship parties and thus external actors can adopt active roles in capability development. Thus, the resources and routines of a company are integrated and activated through interaction with external actors (Johnsen \& Ford, 2006). Indeed, Matthing et al. (2004) suggest that, through proactive customer participations service providers can improve learning and reduce the risk of being overtaken by competitors.

To sum up, the theoretical discussion allows us to pose two propositions: first, suppliers need three types of capabilities to enhance NSD with their customers; and second, suppliers may develop these capabilities through interaction with customers. To empirically ground this frame and to identify the NSD capabilities and the means of their development empirically, a multiple case study was conducted. The following section describes the empirical research design and its key findings.

\section{The Case Study}

The empirical part of the study is a multiple case study. The case study method is often used to explore decisions and behaviors of groups and individuals in inter-organizational relationships (Halinen \& Törnroos, 2005). Moreover, it is an appropriate approach for a research subject that has been insufficiently studied (Eisenhardt, 1989), as is the case here.

The case study consists of three cases, each of which had parallel initiatives in a research project. The cases were 
chosen to execute literal replication logic, which aims to predict similar results (see Yin, 2003, p. 47) and to stress eventual learning from them (see Stake, 1995, p. 4).

In the first case, a consultancy company (Aatos) that specializes in communications, software development, and business-critical IT, develops a novel mobile service with three types of actors: its customer, end customers, and international branches. In the second case, the provider of collaborative and networked business solutions (Taisto) develops an innovative digital marketing channel for the agriculture industry in collaboration with three types of actors: a customer, end customers, and other parties in the industry. In the third case, a company (Urho) that offers advanced IT services and solutions develops a digital platform that supports the design of an innovative new playground. The platform is a result of cooperation with a customer, end customers, and several research institutions. In each case, the service provider includes their customer in the NSD process. Moreover, during each development process, the other actors also considerably affect the collaborative NSD.

Table 1. The empirical data of the study

\begin{tabular}{llll}
\hline Firm & Type of data & Interviewee & Occasion \& Duration \\
\hline Aatos & Interview & CEO & $19.8 .2011,70$ minutes \\
& Home pages, initiative plan & & December 2011 \\
Taisto & Interview & CEO & $19.8 .2011,30$ minutes \\
& Web pages, initiative plan & & December 2011 \\
Urho & Interview & Senior Consultant, & $19.8 .2011,55$ minutes \\
& Interview & Technological Consultant & $24.8 .2011,60$ minutes \\
& Web pages, customer feedback & & September 2011 \\
$\begin{array}{l}\text { Customer } \\
\text { of Urho }\end{array}$ & Interview & Development Manager & $28.9 .2011,30$ minutes \\
$\begin{array}{l}\text { Customer } \\
\text { of Urho }\end{array}$ & Interview & Manager of Community Technology & $28.9 .2011,30$ minutes \\
\hline Ashown & & & \\
\hline
\end{tabular}

As shown in Table 1, the primary data were acquired through six narrative interviews in the course of the NSD processes and therefore reflect the cooperation of the service providers and their customers. The four company interviewees had been closely involved in the NSD processes. Additionally, two customer interviews were included to capture the customer point of view, thus offering dyadic data on the cases. The secondary data consist of documents (e.g., customer feedback inquiries and initiative plans) assembled to support and triangulate the primary data.

The empirical data were analyzed thematically with the help of a theoretical framework, while being conscious of allowing new themes to emerge from the data (Eriksson \& Kovalainen, 2008, p. 219). First, each narrative was individually analyzed and thereafter compared with the others so that patterns could be traced. The analysis, which emphasized NSD capabilities and the means of capability development, reinforced, and showed new aspects of, the earlier theoretical frame. The following section will describe and identify the key findings of the study.

\section{Key Findings}

The research findings stress NSD capabilities and the means of capability development. Capability development is described through the categories of NSD capabilities since separating a capability from its development is difficult.

\subsection{Service- and Structure-based Capabilities}

As with every service development process, each project required technological capabilities. Substance knowledge of the projects was coordinated by R\&D directors and technical engineers. Moreover, in the case of Urho, technological competences were acquired through subcontracts due to project funding requirements. Similarly, Aatos counted on the support of its network partners and international branch in Russia. Besides technological competences, the service providers needed innovation capability because the services were developed by applying novel and innovative methods instead of incrementally changing old systems and habits.

"We had a change here. We moved from the world of closed innovations to involving the customers more openly.” CEO, Aatos

"We sat down and thought about it, and yes, there was a clear opportunity to do things differently." CEO, Taisto 
"There was enthusiasm...for the reason that we were doing things in a new, interesting way." Technological Consultant, Urho

In each case, the development process of a novel service included several interest groups who all had their own requirements and objectives. Thus, the project management capability of each service provider was perceived to be important. In particular, Taisto used its project management skills to gather various network actors with different latent needs together, whereas for Urho it was a means to expedite the project. In addition, Aatos identified the need for a local person who had a clear perception of the actions of distinct actors and their impacts on the status of the project.

Urho carried out the project management through interaction. Furthermore, each service provider handled the development process largely by assigning clear roles and responsibilities. Hence, resource coordination capabilities were strongly stressed. In Aatos, clear role definitions and the independent capability to take risks and further render decisions ensured that unnecessary resource use was diminished. That is, clear responsibilities and roles enabled the right people to be at the right place at the right time to make critical decisions.

"You must have clear roles and responsibility areas so that things proceed among the right people. We cannot work efficiently in a situation where we do not have clear roles and objectives." CEO, Aatos

"We divided roles clearly...otherwise it would not work." Senior Consultant, Urho

In Aatos, responsibilities and roles were divided by emphasizing individuals' skills and competencies and ensuring that customer promises were fulfilled. Urho and Taisto, on the other hand, stressed the implicit and flexible sharing of responsibilities and initiative attitude of employees to contribute to areas outside of traditional roles and defined responsibilities. In two of the cases, the service providers also used resource mobilization capabilities to manage and deploy their own and their partners' valuable but scarce resources. That is, the service providers used mobilization capabilities primarily to allocate personnel and working time in the frame of their project deadlines.

"Resourcing is always a challenge... how we find enough resources." CEO, Taisto

"With the people and resources we have, we cannot manage so many this kinds of projects in a year. So the problem is the lack of resources." Manager of Community Technology, Customer of Urho

\subsection{Interaction-based Capabilities}

In dyadic relationships involving actors participating voluntarily, interaction is the ultimate way to influence a partner. Thus, an influential actor should have an excellent visioning capability to motivate other actors and strengthen the impact of a message (Möller \& Svahn, 2003). In Aatos, visioning capability meant the proactive recognition of customer needs and overall business opportunities. However, for Urho interaction was a means to create a clear future vision as general objects for the project were recognized primarily through dialog between the service provider and the customer. In addition, Taisto understood that the development of a novel and innovative service starts with the specification of customer needs and the overall risks for the parties involved.

"You must understand customer needs, or see a little bit forward in advance. A constant follower strategy just does not give you the most productive and newest projects." CEO, Aatos

"It is a dialog...because we must define together what the actual problem is." Development Manager, Customer of Urho

A general capability to recognize customer needs provided direction for future visioning. In the case of Aatos, the implementation of an envisioned future required the capability to take risks since a developed mobile service consists of several challenges and problematic security issues. Moreover, through taking risks Alpha demonstrated cooperativeness and developed the required level of trust. At the individual level, it meant making independent decisions.

"If you are doing something new, it is always a business risk. Shirking the risks does not generate trust as much as if you really show that you are doing the project together." CEO, Aatos

Each service provider involved its customer, end customers, and other parties in the NSD process. Thus, communication capability was prioritized in the companies. In Urho, face-to-face interaction facilitated the development process and created creativity since dialog between the partners helped to set the objectives of and

direction for cooperation. For Taisto, interaction bound distinct interest groups into the development process. For Aatos, on the other hand, interaction with the customer and end customers enabled crucial feedback. 
"Face-to-face communication brings out the most productive user experiences and methods of involvement." Development Manager, Customer of Urho

"Through interaction we increase the commitment and receive feedback. It is a way to work people into the project and make them commit and express their own thoughts." CEO, Taisto

The capability of creating a cooperative atmosphere is an important element in NSD processes as it helps parties to create relational closeness.

"Cases like this, these kind of new business opportunities emerge only in deep partnerships." CEO, Aatos

It became evident that the service providers stressed both similar and distinct elements of cooperative atmospheres. In the case of Aatos the continuous interaction within and between the service provider and customer generated a cooperative atmosphere as it increased the spread of a similar way of thinking. Moreover, the mutual understanding increased the required trust and commitment because knowing each other made the partners work together for a common purpose. Taisto emphasized the creation of similar commitments because of the high risks of service development. Overall commitment was experienced as a prerequisite for the overall progress of the projects. In Urho and Aatos, the subject of cooperation was considered interesting and strengthened the commitment level.

\subsection{Developing Supplier Capabilities}

Cooperation with several types of actors requires adaptation. Professionals in Aatos believe in the idea of adapting to a customer's way of thinking. In addition, Urho emphasized individuals' adaptation skills and development of competences to help manage changes in its dynamic operational environment. Besides adaptations, Urho resolved inconsistencies and disputes, which could have hampered the cooperative atmosphere, through conversations. Hence, it is suggested that capabilities are partly developed through the joint efforts of individuals. As NSD relationships are primarily relationships between people, capabilities are at certain level the outcome of personal characteristics of individual employees. For instance, as employees of the service providers adapted their behaviors, solved disputes, and bound themselves into the projects, they created cooperative atmospheres.

NSD capabilities resulted primarily from interaction between the service providers and customers, and capabilities were exploited through interaction. That is, the service providers implemented tasks and functions, which required specific capabilities, through cooperation. For instance, objectives, roles, responsibilities, and schedules that were part of the project management capability were defined together by communicating and negotiating over divergent aspects and interests. In addition, interaction-based capabilities partly assisted the development of service- and structure-based capabilities. That is, existing capabilities helped to develop and exploit novel NSD capabilities. For instance, by increasing mutual understanding through communication, the service providers enhanced the cooperative atmospheres.

"The project manager must communicate the same kind of understanding for each project member." CEO, Aatos

"The better the customer and the service provider know each other, or are familiar with each other's thoughts, the more likely it is that they are working together for a common goal.” Technological Consultant, Urho

\section{Concluding Discussion}

The active role of customers in NSD has been found to be a key factor in successful service innovation. NSD studies that involve customers have concentrated mostly on the results of customer participation (e.g., Carbonell et al., 2012; Nicolajsen \& Scupola, 2011), and supplier capabilities that support NSD with customers have not received as much attention. Thus, this study presents three categories of NSD capabilities for suppliers: (1) service-based capabilities; (2) structure-based capabilities; and (3) interaction-based capabilities (see Table 2). The study finds that Croom's (2001) product development capability areas can help us to understand the NSD process when adapted to the context of NSD in customer relationships. Technological (see Carbonell et al., 2009; Matthing et al., 2004), structural (see Menor \& Roth, 2007), and specifically interactive (see Matthing et al., 2004) capabilities play a critical role in the NSD process. That is, the NSD process requires relational closeness (Carbonell et al., 2012; Nicolajsen \& Scupola, 2011). 
Table 2. NSD capabilities of a supplier

\begin{tabular}{lcc}
\hline Service-based capabilities & Structure-based capabilities & Interaction-based capabilities \\
\hline Technological capabilities & Project management capability & Visioning capability \\
& Resource mobilization & Recognizing customer needs \\
& Resource coordination & Risk taking
\end{tabular}

Innovation capability

Communication capability

Capability of creating a cooperative atmosphere

The study recognizes that service providers require strong technological capabilities and the capability to innovate, as new and attractive services are developed by following novel approaches instead of incrementally changing traditional ways. That is, service providers need the capability to bundle existing knowledge in novel ways (den Hertog et al., 2010). The study finds that a project management capability, executed largely by coordinating scarce resources, is required for a relationship to operate successfully for its duration. This capability consists of processes, routines, and infrastructure that support the relationship (Jarratt, 2004) that needs to be structured and managed (Kindström et al., 2012).

The capability to recognize customer needs is a vital part of future visioning as it enables a proactive search for potential customers and eventually leads to a sustainable competitive advantage. Therefore, the capability of service providers to understand and analyze customer markets (Menor \& Roth, 2007) and thus build up deep customer knowledge (Kindström et al., 2012) should be emphasized. In addition, the capability to communicate and the capability to create a cooperative atmosphere should be prioritized. Continuous dialog between a service provider and a customer creates a cooperative atmosphere as it enhances reciprocal understanding, trust, and commitment. Indeed, close interaction with customers helps service providers to understand and deliver the value propositions (Kindström et al., 2012) and thus cooperativeness has been observed to be a result of trust (Jarratt, 2004).

The study finds that NSD capabilities primarily result from interaction between the service providers and customers and the exploitation of capabilities is also initiated through interaction with other parties (see also Johnsen \& Ford, 2006; Croom, 2001). The study shows that the development of individual capabilities overlap and are embedded within each other. The dynamic capability approach (e.g., Teece et al., 1997; Zollo \& Winter, 2002) shows that existing capabilities can help to develop and exploit novel ones, particularly if they are personal characteristics (see also Helfat \& Peteraf, 2003). This study argues that interaction-based capabilities in particular support the creation of service- and structure-based capabilities (see also Croom, 2001).

Managers that actively seek to involve customers in their NSD processes should establish close relationships with their key customers because interaction provides the necessary tools to gather the information required for successful service innovation. Therefore, this study identifies three NSD capability categories, including capabilities to assist managers to initiate, manage, apply, and (if required) terminate customer relationships in pursuit of innovative services. The second benefit of this study stems from the means by which specific capabilities can be developed. Service providers should thus enhance direct interaction with their customers through processes and technologies that create open communication. Moreover, managers must understand that existing capabilities can facilitate the development and exploitation of novel NSD capabilities, particularly if they are based on the personal characteristics of individuals. In that case, the required capabilities should be deployed through teamwork, work rotation, training, or education.

The reliability of the study is improved through careful evaluation and selection of the individual cases and interviewees. Furthermore, using distinct sources of data assists data triangulation and a full description of the research design makes the study capable of repetition. A limitation of the study is that it is for the most part informed by the service provider perspective, creating an avenue for future research focusing on NSD from the customer point of view. Moreover, it would be beneficial to study which NSD capabilities are particularly important at each stage of the development process. Consequently, research that examines the longitudinal aspects of NSD with customers would be welcome. 


\section{References}

Alam, I., \& Perry, C. (2002). A customer-oriented new service development process. Journal of Services Marketing, 16(6), 515-534. http://dx.doi.org/10.1108/08876040210443391

Carbonell, P., Rodríguez-Escudero, A.I., \& Pujari, D. (2009). Customer involvement in new service development: an examination of antecedents and outcomes. Journal of Product Innovation Management, 26(5), 536-550. http://dx.doi.org/10.1111/j.1540-5885.2009.00679.x

Carbonell, P., Rodríguez-Escudero, A.I., \& Pujari, D. (2012). Performance effects of involving lead users and close customers in new service development. Journal of Service Marketing, 26(7), 497-509. http://dx.doi.org/10.1108/08876041211266440

Coviello, N.E., \& Joseph, R.M. (2012). Creating major innovations with customers: insights from small and young technology firms. Journal of Marketing, 76(6), 87-104. http://dx.doi.org/10.1509/jm.10.0418

Croom, S.R. (2001). The dyadic capabilities concept: examining the process of key supplier involvement in collaborative product development. European Journal of Purchasing \& Supply Management, 7(1), 29-37. http://dx.doi.org/10.1016/S0969-7012(00)00019-8

den Hertog, P., van der Aa, W., \& de Jong, M.W. (2010). Capabilities for managing service innovation: towards a conceptual framework. Journal of Service Management, 21(4), 490-514. http://dx.doi.org/10.1108/09564231011066123

Eisenhardt, K.M. (1989). Building theories from case study research. Academy of Management Review, 14(4), $532-550$.

Eisenhard, K.M., \& Martin, J.A. (2000). Dynamic capabilities: what are they? Strategic Management Journal, 2l(10-11), http://dx.doi.org/10.1002/1097-0266(200010/11)21:10/11<1105::AID-SMJ133>3.0.CO;2-E

1105-1121.

Eriksson, P., \& Kovalainen, A. (2008). Qualitative methods in business research. London: Sage Publications, Inc.

Gadde, L.E., \& Håkansson, H. (2001). Supply network strategies. Chichester: John Wiley \& Sons.

Halinen, A., \& Törnroos, J.-Å. (2005). Using case methods in the study of contemporary business networks. Journal of Business Research, 58(9), 1285-1297. http://dx.doi.org/10.1016/j.jbusres.2004.02.001

Helfat, C.E., \& Peteraf, M.A. (2003). The dynamic resources-based view: capability lifecycles. Strategic Management Journal, 24(10), 997-1010. http://dx.doi.org/10.1002/smj.332

Jarratt, D. (2004). Conceptualizing a relationship management capability. Marketing Theory, 4(4), 287-309. http://dx.doi.org/10.1177/1470593104047637

Johnsen, R.E., \& Ford, D. (2006). Interaction capability development of smaller suppliers in relationships with larger $\begin{array}{llll}\text { customers. } & \text { Industrial } & \text { Marketing }\end{array}$ http://dx.doi.org/10.1016/j.indmarman.2006.05.005

Kindström, D., Kowalkowski, C., \& Sandberg, E. (2012). Enabling service innovation: a dynamic capability approach. Journal of Business Research. In Press. http://dx.doi.org/10.1016/j.jbusres.2012.03.003

Lin, M.-J. J., \& Huang, M.-H. (2013). The impact of customer participation on NPD performance: the mediating role of inter-organization relationship. Journal of Business \& Industrial Marketing, 28(1), 3-15. http://dx.doi.org/10.1108/08858621311285679

Martin, C.R., \& Horne, D.A. (1993). Services innovations: successful versus unsuccessful firms. International Journal of Services Industry Management, 1(4), 49-65.

Matthing, J., Sandén, B., \& Edvardsson, B. (2004). New service development: learning from and with customers. International Journal of Service Industry Management, 15(5), 479-498. http://dx.doi.org/10.1108/09564230410564948

Menor, L.J., \& Roth, A.V. (2007). New service development competence in retail banking: construct development and measurement validation. Journal of Operations Management, 25(4), 825-846. http://dx.doi.org/10.1016/j.jom.2006.07.004

Möller, K., \& Svahn, S. (2003). Managing strategic nets: a capability perspective. Marketing Theory, 3(2), 209-234. http://dx.doi.org/10.1177/14705931030032002 
Nicolajsen, H.W., \& Scupola, A. (2011). Investigating issues and challenges for customer involvement in business service innovation. Journal of Business \& Industrial Marketing, 26(5), 368-376. http://dx.doi.org/10.1108/08858621111144424

Ritter, T., \& Gemünden, H.G. (2003). Network competence: its impact on innovation success and its antecedents. Journal of Business Research, 56(9), 745-755. http://dx.doi.org/10.1016/S0148-2963(01)00259-4

Slater, S.F., \& Narver, J.C. (1998). Customer-led and market-oriented: let's not confuse the two. Strategic Management Journal, 19(10), 1001-1006. http://dx.doi.org/10.1002/(SICI)1097-0266(199810)19:10<1001::AID-SMJ996>3.0.CO;2-4

Stake, R.E. (1995). The art of case study research. London: Sage Publications, Inc.

Teece, D.J., Pisano, G., \& Shuen, A. (1997). Dynamic capabilities and strategic management. Strategic Management Journal, $18(7)$, http://dx.doi.org/10.1002/(SICI)1097-0266(199708)18:7<509::AID-SMJ882>3.0.CO;2-Z

Wang, C.L., \& Ahmed, P.K. (2007). Dynamic capabilities: a review and research agenda. International Journal of Management Reviews, 9(1), 31-51. http://dx.doi.org/10.1111/j.1468-2370.2007.00201.x

Yin, R.K. (2003). Case study research: Design and methods. United States of America: Sage Publications, Inc.

Zollo, M., \& Winter, S.G. (2002). Deliberate learning and the evolution of dynamic capabilities. Organization Science, 13(3), 339-351. http://dx.doi.org/10.1287/orsc.13.3.339.2780 